\title{
Regulatory sRNAs in Cyanobacteria
}

\author{
Jinlu Hu and Qiang Wang ${ }^{2,3 *}$ \\ ${ }^{1}$ School of Life Sciences, Northwestern Polytechnical University, Xi'an, China, ${ }^{2}$ Key Laboratory of Algal Biology, Institute \\ of Hydrobiology, The Chinese Academy of Sciences, Wuhan, China, ${ }^{3}$ University of the Chinese Academy of Sciences, \\ Beijing, China
}

\section{OPEN ACCESS}

Edited by:

Weiwen Zhang,

Tianjin University, China

Reviewed by:

Yingchun Wang,

Institute of Genetics and

Developmental Biology (CAS), China

Harvey J. M. Hou,

Alabama State University,

United States

Aigen Fu,

Northwest University, China

*Correspondence:

Qiang Wang

wangqiang@ihb.ac.cn

Specialty section:

This article was submitted to

Microbiotechnology, Ecotoxicology

and Bioremediation,

a section of the journal

Frontiers in Microbiology

Received: 03 July 2018

Accepted: 19 September 2018

Published: 19 October 2018

Citation:

Hu J and Wang Q (2018)

Regulatory sRNAs in Cyanobacteria.

Front. Microbiol. 9:2399.

doi: 10.3389/fmicb.2018.02399
As the transcriptional and post-transcriptional regulators of gene expression, small RNAs (sRNAs) play important roles in every domain of life in organisms. It has been discovered gradually that bacteria possess multiple means of gene regulation using RNAs. They have been continuously used as model organisms for photosynthesis, metabolism, biotechnology, evolution, and nitrogen fixation for many decades. Cyanobacteria, one of the most ancient life forms, constitute all kinds of photoautotrophic bacteria and exist in almost any environment on this planet. It is believed that a complex RNA-based regulatory mechanism functions in cyanobacteria to help them adapt to changes and stresses in diverse environments. Although lagging far behind other model microorganisms, such as yeast and Escherichia coli, more and more non-coding regulatory sRNAs have been recognized in cyanobacteria during the past decades. In this article, by focusing on cyanobacterial sRNAs, the approaches for detection and targeting of sRNAs will be summarized, four major mechanisms and regulatory functions will be generalized, eight types of cis-encoded sRNA and four types of trans-encoded sRNAs will be reviewed in detail, and their possible physiological functions will be further discussed.

Keywords: small RNA, cyanobacteria, sRNA identification, regulatory functions, physiological roles

\section{INTRODUCTION}

RNAs from cells that do not display messenger RNAs (mRNAs), ribosomal RNAs (rRNAs), or transfer RNAs (tRNAs) functions include a wide class of molecules, usually denominated as small RNAs (sRNAs) or non-coding RNAs (ncRNAs) (Storz et al., 2004; Waters and Storz, 2009). As the transcriptional and post-transcriptional regulators of gene expression, sRNAs play important roles in every domain of life in organisms (Raghavan et al., 2011). Different from protein-coding regions specified by genetic codes, sRNAs have no clear-cut signatures that represent their boundaries as regulatory RNAs or even their occurrence in a genome. They play key roles in various basic processes in organisms, including structural maintenance of chromosome (Storz, 2002; Volpe et al., 2002), regulation of stability and translation of mRNAs (Storz et al., 2004), translocation and stability of proteins (Huttenhofer et al., 2005; Hüttenhofer and Vogel, 2006), metabolic reactions (Park et al., 2010), stress responses (Romby et al., 2006), and pathogenesis (Lee and Groisman, 2010).

Abbreviations: nt, nucleotides; sRNA, small RNA. 
In prokaryotes, the length of sRNAs usually ranges from 50 to 500 nucleotides (nt). The sRNAs were known in prokaryotes as regulators for years before the first microRNA (miRNA) and short interfering RNA (siRNA) were found in eukaryotes. It was reported that a $\sim 108$ nt RNA I blocked ColE1 plasmid replication by base pairing with the RNA, which was cleaved to produce the replication primer (Stougaard et al., 1981; Tomizawa et al., 1981). Shortly after that, a $\sim 70$ nt RNA transcribed from the pOUT promoter of Tn10 transposon was discovered preventing translation of the transposase mRNA and repressing transposition (Simons and Kleckner, 1983). Subsequently, the 174 nt MicF RNA was identified as the first chromosomally encoded sRNA in Escherichia coli (E. coli) and plays a role in inhibiting translation of the mRNA encoding OmpF, the major outer membrane porin (Mizuno et al., 1984). These sRNAs were identified by multicopy phenotypes, by gel analysis due to their abundance, or by serendipity (Wassarman et al., 1999; Waters and Storz, 2009). During the past decade, the importance of this amazing group of RNAs has been widely recognized in various organisms (Mattick, 2001; Huttenhofer et al., 2002; Storz, 2002; Huttenhofer et al., 2005; Raghavan et al., 2011). Due to recent technical advancements, e.g., deep sequencing, computational searches, and tilling microarrays with full-genome coverage (Weinberg et al., 2007; Landt et al., 2008; Livny et al., 2008; Sittka et al., 2008), many new candidate sRNAs have now been predicted in E. coli and other bacteria. In E. coli, systematic computational analyses have predicted the existence of hundreds of sRNAs in the past few decades (Livny and Waldor, 2007); however, only about 80 sRNAs have been experimentally validated (Waters and Storz, 2009). Above all, the function of many sRNAs remains unknown.

Cyanobacteria constitute a wide variety of photoautotrophic bacteria that undergo oxygenic photosynthesis and grow under extremely diverse environmental conditions on Earth, such as oceans, freshwater, rocks surface, desert soils, or even polar regions. The existence of cyanobacteria can be traced back possibly up to 3-5 billion years (Schopf, 1993), and they have long been recognized as important model organisms for research in aspects such as photosynthesis (Pisciotta et al., 2010; Chen et al., 2015), metabolism (Tamagnini et al., 2002), stress responses (Wang et al., 2008; Ma et al., 2017), biotechnology (Abed et al., 2009; Zhan and Wang, 2018), evolution (Flores and Herrero, 2008), and nitrogen fixation (Goebel et al., 2010). Particularly, cyanobacteria are a group of unicellular aquatic prokaryotes that possess certain properties such as fast growth, short life cycle, and spontaneously transformability, which have entitled them to be one of simple experimental systems and the most promising feedstock for bioenergy generation (Quintana et al., 2011; Giordano and Wang, 2018).

The majority of data on bacterial sRNAs originated from enterobacteria analysis. To date, in cyanobacteria, identified or functionally characterized sRNAs have only been reported in a few studies. In our previous works, by deep RNAsequencing (RNA-seq), a total number of 5261 putative sRNAs in Synechocystis sp. PCC 6803 were revealed from the genome and its four megaplasmids, providing a comprehensive overview of sRNAs in the model organism (Xu et al., 2014; Hu et al., 2017). It is very likely that cyanobacteria, present in almost any environment with a long evolutionary history, have evolved a complex RNA-based regulatory network to respond to environmental changes and stress, analogously to enterobacteria. Here, we will review the research works on cyanobacterial sRNAs, including approaches for sRNAs detecting and targeting, their mechanisms of action and regulatory functions, and their possible physiological functions.

\section{IDENTIFICATION OF SRNAs AND THEIR TARGETS IN CYANOBACTERIA}

Due to divergence in sequences, structures, and functions, cyanobacterial sRNAs have no common identifiers. Nevertheless, biocomputational prediction, tiling microarrays, and pyrosequencing revealed that many candidate sRNAs have been existing in some cyanobacterial model organisms for the past several decades. The combination of computational and experimental methods used to identify sRNAs can help us understand sRNAs better and is likely to provide the complete sRNAs definition soon.

\section{Biocomputational Prediction}

The most important aspect of sRNA research includes designing the methods used for the prediction of sRNA and their targets. These investigations have been carried out in-depth in the last few years. The standard procedures used to predict bacterial sRNAs and their targets include these three steps: 1. identifying conserved sequences and/or structure features in intergenic regions, 2. clustering and comparing of pairwise or multiple alignments, and 3 . scoring based on structural features of predicted RNAs, which were reviewed in detail by Backofen and Hess (2010).

A mass of sRNAs has been predicted based on comparative genomics analysis and non-comparatives screenings (Backofen and Hess, 2010; Kopf et al., 2014). Meanwhile, as a key bottleneck, the targets identification of these sRNAs is an immediate requirement for further progress in this field. Many developed target-prediction tools and related software for bacteria may be worth learning (Table 1). Some examples include TargetRNA (Tjaden et al., 2006; Tjaden, 2008), sequence-based scoring combined with stacking (Mandin et al., 2007), RNAplex (Tafer and Hofacker, 2008), sRNATarget (Zhao et al., 2008; Cao et al., 2009), RNAup (Muckstein et al., 2006), RNAhybrid (Rehmsmeier et al., 2004), GLASSgo (Lott et al., 2018), especially CopraRNA (Wright et al., 2014), and IntaRNA (Busch et al., 2008). Among those, CopraRNA is the latest asset of the Freiburg RNA tools Web server, which incorporates and extends the functions of IntaRNA to better predict targets and interaction domains of bacterial sRNA. The GLASSgo allows discovery of the homologous sRNA sequences, which is often the first step in the functional characterization and targets prediction of a sRNA. All of the earlier mentioned tools can be used to predict targets of cyanobacterial sRNA, if used reasonably. There is a representative report that possible sRNAs target genes were predicted using the IntaRNA tool, and then functional categorization analysis using gene ontology (GO) assignment programs and functional 
TABLE 1 | Summary of SRNA targets prediction tools mentioned in the text.

\begin{tabular}{|c|c|c|c|c|}
\hline Tools & Algorithm & Advantage & Limitation & Source \\
\hline $\begin{array}{l}\text { Sequence-based } \\
\text { scoring combined with } \\
\text { stacking }\end{array}$ & $\begin{array}{l}\text { Target prediction based } \\
\text { on sequence }\end{array}$ & $\begin{array}{l}\text { 1. Simplicity } \\
\text { 2. Easy calculating of significance } \\
\text { of the found matches }\end{array}$ & $\begin{array}{l}\text { Neglecting some factors } \\
\text { that may contribute to } \\
\text { RNA-RNA interaction, such } \\
\text { as RNA secondary } \\
\text { structure or the role of Hfq }\end{array}$ & Mandin et al., 2007 \\
\hline RNAplex & $\begin{array}{l}\text { Thermodynamic } \\
\text { scoring of mRNA-sRNA } \\
\text { mixed duplexes }\end{array}$ & $\begin{array}{l}\text { 1. Providing a much more realistic } \\
\text { model of RNA-RNA interaction, as } \\
\text { compared to approaches based on } \\
\text { sequence complementarity } \\
\text { 2. Very fast } \\
\text { 3. Easy calculating of significance } \\
\text { of the found hits }\end{array}$ & $\begin{array}{l}\text { Neglecting intra-molecular } \\
\text { base pairs }\end{array}$ & $\begin{array}{l}\text { Tafer and Hofacker, } \\
2008\end{array}$ \\
\hline RNAhybrid & $\begin{array}{l}\text { Thermodynamic } \\
\text { scoring of mRNA-sRNA } \\
\text { mixed duplexes }\end{array}$ & $\begin{array}{l}\text { 1. Providing a much more realistic } \\
\text { model of RNA-RNA interaction, as } \\
\text { compared to approaches based on } \\
\text { sequence complementarity } \\
\text { 2. Very fast } \\
\text { 3. Easy calculating of significance } \\
\text { of the found hits }\end{array}$ & $\begin{array}{l}\text { Neglecting intra-molecular } \\
\text { base pairs }\end{array}$ & $\begin{array}{l}\text { Rehmsmeier et al., } \\
2004\end{array}$ \\
\hline CopraRNA & $\begin{array}{l}\text { Handling accessibility in } \\
\text { mRNA-sRNA } \\
\text { interactions }\end{array}$ & $\begin{array}{l}\text { Incorporating and extending the } \\
\text { functionality of IntaRNA to better } \\
\text { predict targets and interaction } \\
\text { domains of SRNA }\end{array}$ & & Wright et al., 2014 \\
\hline GLASSgo & $\begin{array}{l}\text { Combines an iterative } \\
\text { BLAST strategy with } \\
\text { pairwise identity filtering } \\
\text { and a graph-based } \\
\text { clustering method }\end{array}$ & $\begin{array}{l}\text { 1. Very fast and high specificity } \\
\text { 2. Easy-to-use }\end{array}$ & & Lott et al., 2018 \\
\hline
\end{tabular}

annotation tool DAVID (Dennis et al., 2003; Huang et al., 2008) can be used, evidencing that sRNAs are involved in various metabolic pathways (Xu et al., 2014).

However, bioinformatic analysis alone is still full of high false positive rates. There are three main reasons for high false positive rates in cyanobacteria: (1) most target genes are at different genomic loci relative to their sRNAs; (2) although some sRNAs have single targets, others could regulate a multitude of gene expression; and (3) targets predictions of protein-modifying sRNAs also can be a challenge depending on the nature and understanding of the target characteristics. It is significantly necessary to identify more sRNAs targets of cyanobacteria by combining computational and experimental approaches in future. Georg et al. (2014) proved the interaction between the ribosome-binding regions of the $p s a L, p s a J, c h l N$, and $c p c A$ mRNA and sRNA PsrR1 by the combination of the CopraRNA tool and experimental analysis.

\section{Microarray Analysis}

Microarray analysis is the approach that uses microchips conjugated with probes (short DNA elements) for the screening of large-scale gene expression. Labeled nucleic acid samples 
are applied to the microchips and then hybridized to specific probes; the interaction is identified by imaging and subsequent data processing. Microarray analysis is a strong tool for the detection of sRNA, especially antisense sRNA (asRNA), whose function is mainly determined by mere sequence complementarity rather than structural characteristics or specific sequence. Since computational screens rarely find asRNAs, the superiority and preferences are important to novel sRNA by a correlation between the prediction and the actual presence of a terminator.

High-coverage genome-wide microarrays had been used to screen for the presence of sRNAs in Prochlorococcus MED4 and Synechocystis sp. PCC 6803 (Steglich et al., 2008; Georg et al., 2009). Twelve new ncRNAs and 24 asRNAs were identified though microarray analyses in Prochlorococcus MED4 and then 12 ncRNAs were independently verified by experiment (Steglich et al., 2008). In Synechocystis sp. PCC 6803, a novel transcriptome microarray was designed as an efficient tool for the verification of the possible regulation of the newly found asRNAs and ncRNAs. This array includes probe sets for all protein-coding genes as well as for all other transcripts. Totally, 11 out of 73 asRNAs and 27 out of 60 intergenic ncRNAs had been predicted with high microarray expression levels, based on the existence of a Rhoindependent terminator using this approach (Georg et al., 2009). Five ncRNAs of these have been earlier reported in a comparative genomics study (Voss et al., 2009).

\section{RNA-Sequence Approach}

Within the last few years, RNA-sequencing technology has completely changed the global identification of sRNAs in cyanobacteria and evoked a research wave in this field. As a powerful analytical tool, RNA-seq, especially differential RNAseq (dRNA-seq), not only provides an in-depth understanding of changes in gene expression, but also the details of all promoters active at a given time, thus providing effectively an insight into the state of transcription. A dRNA-seq has established a genome-wide map of Synechocystis sp. PCC 6803 with 3,527 transcriptional start sites (TSSs) (Mitschke et al., 2011a). Onethirds $(1,112)$ were found on the reverse complementary strand of 866 genes (aTSS, antisense RNA TSS), suggesting a large number of antisense transcriptions. The prediction of ncRNAs came from 429 seemingly orphan TSSs (nTSS, non-coding RNA TSS) located in intergenic regions. Genome-wide maps of active TSSs have been established and identified 4,091 transcriptional units under 10 different conditions related to photosynthetic growth (Kopf et al., 2014). Besides, several sRNAs with an intriguing expression pattern have been reported. In addition, a deep RNA-seq analysis focusing on low molecular weight RNAs ( $\leq 200 \mathrm{nt}$ ) predicted 5,261 and 3,380 novel transcribed sRNA regions from the genome and the four megaplasmids in Synechocystis sp. PCC 6803 under normal and high light conditions. Totally, 14 of these molecules, including three from different megaplasmids, were confirmed by RNA blot hybridization (Xu et al., 2014; Hu et al., 2017).

However, there are a lot of data noise and false-positives in the biocomputational prediction, tiling microarrays, or RNA-sequence approaches. So, the subsequent verification by experimental approaches is essential for the identification of
sRNAs and their functional verification, e.g., RACE, Northern blot analysis, and mutant strains of overexpression/knockdown.

\section{REGULATORY FUNCTIONS OF CYANOBACTERIAL SRNAS}

The sRNAs are important transcriptional and posttranscriptional regulators of gene expression in every domain of life, modulating mRNA stability, DNA maintenance, DNA silencing, transcription, and translation (Waters and Storz, 2009). They achieve these diverse outcomes by multiple mechanisms, such as changes in protein binding, base pairing with other RNAs, and interactions with DNA.

\section{sRNAs That Modulate Protein Activity}

A small class of sRNA would interact with special target protein in order to function. Three classes of the well-studied sRNAs of those have the typical characteristics of protein-binding sRNA. The RNase P RNA has intrinsic activity, e.g., the RNase P RNA is required for survival in Synechocystis sp. PCC 6803 (Tous et al., 2001), while 4.5S RNA and tmRNA provide basic functions for a ribonucleoprotein particle. In contrast, another protein-binding sRNA (6S RNA) acts in a regulation to antagonize cognate proteins activities by mimicking other nucleic acids structures (Banta et al., 1992; Watanabe et al., 1997, 1998; Sugita et al., 2007). In Synechocystis sp. PCC 6803, nTSS (sRNA TSS) for 4.5S RNA $(f f)$, 6S RNA (ssaA), RNase P RNA ( $r p p B)$, and tmRNA (ssrA) were consistent with the published experimental data or genome an notation (Mitschke et al., 2011a).

The >100 new 6S RNA homologs were computationally identified in diverse eubacterial lineages and their conserved features suggested that they bind to RNA polymerase by mimicking the DNA template structure in an open promoter complex (Barrick et al., 2005). In 1997, 6Sa RNA was first isolated as a novel sRNA using an elaborate biochemical protocol from the unicellular cyanobacterium Synechococcus PCC 6301 (Watanabe et al., 1997). The accumulation of 6Sa RNA was observed in all cell stages and its level was significantly decreased in the stationary phase, which suggests that 6Sa RNA plays a role in cell division. Later, 6Sa RNA was recognized as 6S RNA homologs by GenBank (Barrick et al., 2005). Axmann et al. (2007) reported that two distinct types of 6S RNAs were accumulated and regulated during growth and the diel cycle in Prochlorococcus MED4. In order to control the timing of cell division and rhythmic regulation of gene expression, these 6S RNAs may switch between two different conformations after binding to trans-acting proteins or other unknown factors (Nair et al., 2002; Ditty et al., 2003; Axmann et al., 2007).

Ribonuclease P (RNase P) is a universal enzyme necessary for tRNA maturation. In cyanobacteria, the enzyme is composed of a protein subunit by $r m p A$ and an RNA subunit by $r n p B$. The RNA subunit was the catalytic component of the enzyme and can precisely perform endonucleolytic cleavage of tRNA precursors to produce a mature $5^{\prime}$ end in the absence of the protein subunit (Frank and Pace, 1998; Tous et al., 2001; Schon et al., 2002). In Synechocystis, for maturation of the dimeric precursors, it needed 
to be cleaved at two positions by RNase $\mathrm{P}$, corresponding to the mature $5^{\prime}$ ends of tRNA ${ }^{\mathrm{Tyr}}$ and $\mathrm{tRNA}{ }^{\mathrm{Thr}}$, respectively (Kaneko and Tabata, 1997; Tous et al., 2001). Besides, RNase P was also involved in the $5^{\prime}$ processing of some stable RNAs, e.g., 4.5S RNA and tmRNA (Tous et al., 2001).

The tmRNA, which has been named to reflect its tRNAlike and mRNA-like properties, was first found in E. coli (Ray and Apirion, 1979) and then reported in many other bacteria (Brown et al., 1990; Tyagi and Kinger, 1992; Ushida et al., 1994; Fleischmann et al., 1995; Williams and Bartel, 1996). Watanabe et al. (1998) reported the first evidence of tmRNA existence in cyanobacteria, and its coding gene was temporarily named as $s s r A$. This study suggested that tmRNA functioned not only when cells divided actively, but also when cells growth stopped by reason of a fairly high level of tmRNA throughout the cell cycle. Although it has not experimentally analyzed the Prochlorococcus tmRNA so far, it would consist of two separate molecules from a common precursor in silico analyses (Keiler et al., 2000; Gaudin et al., 2002; Axmann et al., 2005).

\section{Cis-Encoded Base Pairing sRNAs}

Different from the protein-binding sRNAs mentioned earlier, most characterized sRNAs have complete complementarity or limited complementarity with their target mRNA by base pairing to regulate gene expression (Waters and Storz, 2009). Cisencoded asRNAs are transcribed from the opposite strand of the target gene and share complete complementarity with target mRNA. Most asRNAs reported are heavy regulatory elements and commonly encoded in accessory elements such as transposons and plasmids in bacteria (Wagner et al., 2002; Brantl, 2007). In cyanobacteria, all asRNAs found to date are chromosomally encoded RNAs (Table 2). Cis-encoded asRNAs has a great advantage in a number of cyanobacteria, for example, asRNAs amounting to $26 \%$ of all genes were reported in Synechocystis sp. PCC 6803 (Georg et al., 2009; Mitschke et al., 2011a) and 39\% in Anabaena sp. PCC 7120 (Mitschke et al., 2011b). Thus, cis-encoded chromosomal asRNAs may have an important role in cyanobacterial regulatory networks. In cyanobacteria, cisencoded asRNA represent the most investigated class of sRNA by far. However, the list of asRNAs is far from complete, especially for detailed mechanisms.

Most of cis-encoded chromosomal asRNAs reported so far regulate essential genes expression in response to environmental stresses, optimizing gene function and cell economy. A cisencoded asRNA IsrR (iron stress-repressed RNA), which is the first well studied, was reported to play a role in protecting PSI complex from photo-induced damage in Synechocystis sp. PCC 6803 (Dühring et al., 2006). The IsrR RNA regulates the expression of target gene isiA, which forms a supercomplex around PSI under three different stress conditions: oxidative stress, high light, and iron limitation. Analysis clearly showed that IsrR overexpression strongly diminishes the IsiA-PSI supercomplexes number under iron stress, whereas isrR depletion leads to premature isiA expression. The IsrR appears to be expressed constitutively under moderate iron starvation to suppress isiA expression. In this case, IsrR filters out transient environmental stress signals and results in a delayed isiA expression in the early phase, but it is depleted more quickly during the stress recovery (Legewie et al., 2008).

An asRNA ( $\alpha$-furA RNA) has a complete furA mRNA coding sequence in the nitrogen-fixing Anabaena sp. PCC 7120, which transcribed in the same transcriptional level as alr1690 (Hernández et al., 2006). Disruption of the $\alpha$-furA-alr1690 mRNA increases the level of FurA protein and the resulting mutant shows an iron-deficient phenotype, indicating the biological correlation of this asRNA (Hernandez et al., 2010). Meanwhile, in Microcystis aeruginosa PCC 7806 and Synechocystis sp. PCC 6803, it has identified other three anti-fur RNAs (Martin-Luna et al., 2011; Sevilla et al., 2011), indicating that anti-fur RNAs are highly homologous in cyanobacteria.

The PsbA2R and PsbA3R, two asRNAs located in the $5^{\prime}$ untranslated region ( $5^{\prime} \mathrm{UTR}$ ) of target genes $p s b A 2$ and $p s b A 3$, encode D1 protein of photosystem II in the thylakoid membrane of Synechocystis sp. PCC 6803 (Sakurai et al., 2012). The expression of PsbA2R and PsbA3R is shown to be upregulated by light and downregulated by darkness, similar to the expression of their target mRNA, and acts as a positive regulator of cell growth. These results of the PsbA2R $(-)$ mutant strain showed that PsbA2R was a positive factor and could achieve a maximum level of D1 synthesis under some environmental conditions.

The RuBisCO catalyzes carbon fixation and is the most abundant protein in leaves, summing up to $50 \%$ of the soluble leaf protein in $\mathrm{C} 3$ plants and to $30 \%$ in C4 plants (Feller et al., 2008). The large chain of RuBisCO is encoded by the $r b c L$ gene in cyanobacteria and land plant (Spreitzer and Salvucci, 2002). In our previous study, the 113 nt asRNA RblR that is completely complementary to its target gene $r b c L$ was identified in Synechocystis sp. PCC 6803 (Hu et al., 2017). Analysis clearly showed that RblR has a positive regulation on $r b c L$ gene expression under several stress conditions and suppressing RblR adversely affects carbon assimilation.

The sRNA-mRNA interactions described earlier have been described one by one. Some asRNAs have been discovered to modulate the expression of genes in operons by coordinate regulation or discoordinate regulation in cyanobacteria (Figure 1). In some cases, the activity of sRNA activates or suppresses all genes in the operon at the same time (coordinate regulation). The first reported asRNA is a cisencoded chromosomal asRNA, which is complementary to the gvp $A B C$ operon and involved in gas vesicles formation in Calothrix sp. PCC 7601 (Csiszàr et al., 1987). Therefore, this asRNA can form a homologous duplex with three transcripts of the gvpABC operon, which can damage translation and/or modify mRNA stability. Another cis-asRNA As1_flv4, derived from the flv4-2 operon, could be transiently expressed in Synechocystis sp. PCC 6803 under the limitation of inorganic carbon (Ci) (Eisenhut et al., 2012). During the early phase of low carbon acclimation, As1_flv4 plays roles in Ci-dependent regulation of Flv4-2 proteins by establishing safety threshold and transferring expression in time. The respective asRNA of the flv42 operon acts as a buffer mechanism to avoid premature operon expression under stress (Zhang et al., 2009, 2012). The CoaR is a negative regulator of slr0847 (coaD) and slr0848 operon, which is responsible for the synthesis of coenzyme A (CoA) and 
TABLE 2 | Cis-encoded antisense sRNA indentified in cyanobacteria.

\begin{tabular}{|c|c|c|c|c|c|c|}
\hline sRNA & TSS & Length & Target gene & Function & Species & Source \\
\hline IsrR & 1518034 & $177 \mathrm{nt}$ & isiA & $\begin{array}{l}\text { The protection of } \\
\text { the PSI complex } \\
\text { against } \\
\text { photo-induced } \\
\text { damage }\end{array}$ & $\begin{array}{l}\text { Synechocystis sp. } \\
\text { PCC } 6803\end{array}$ & Dühring et al., 2006 \\
\hline$\alpha$-fur RNA & 2018583 & $2200 \mathrm{nt}$ & $\alpha$-fur-alr1690 & $\begin{array}{l}\text { Regulating } \\
\text { photosynthetic } \\
\text { machinery }\end{array}$ & $\begin{array}{l}\text { Anabaena sp. PCC } \\
7120, \text { conserved in } \\
\text { cyanobacteria }\end{array}$ & $\begin{array}{l}\text { Hernández et al., } \\
2006\end{array}$ \\
\hline PsbA2R, PsbA3R & 7210,1820016 & $\begin{array}{l}130 \text { and } 220 \mathrm{nt} \\
160 \text { and } 180 \mathrm{nt}\end{array}$ & $p s b A 2, p s b A 3$ & $\begin{array}{l}\text { Achieving a } \\
\text { maximum level of } \\
\text { D1 synthesis }\end{array}$ & $\begin{array}{l}\text { Synechocystis sp. } \\
\text { PCC } 6803\end{array}$ & Sakurai et al., 2012 \\
\hline RbIR & c2478718 & $113 \mathrm{nt}$ & $r b c L$ & $\begin{array}{l}\text { Regulating } \\
\text { photosynthetic } \\
\text { machinery }\end{array}$ & $\begin{array}{l}\text { Synechocystis sp. } \\
\text { PCC } 6803\end{array}$ & Hu et al., 2017 \\
\hline gvp asRNA & $\begin{array}{l}56 \text { bp upstream } \\
\text { from the start } \\
\text { codon of the gvpA } \\
\text { gene }\end{array}$ & About $420 \mathrm{nt}$ & gvpABC operon & $\begin{array}{l}\text { Involved in the } \\
\text { formation of gas } \\
\text { vesicles }\end{array}$ & $\begin{array}{l}\text { Calothrix sp. PCC } \\
7601\end{array}$ & Csiszàr et al., 1987 \\
\hline As1_flv4 & 166849 & 500 and $280 \mathrm{nt}$ & flv4-2 operon & $\begin{array}{l}\text { Photoprotection of } \\
\text { photosystem II } \\
\text { under low carbon } \\
\text { conditions }\end{array}$ & $\begin{array}{l}\text { Synechocystis sp. } \\
\text { PCC } 6803\end{array}$ & $\begin{array}{l}\text { Eisenhut et al., } \\
2012\end{array}$ \\
\hline CoaR & 2867076 & $124 \mathrm{nt}$ & $\begin{array}{l}\text { slr0847-s/r0848 } \\
\text { operon }\end{array}$ & $\begin{array}{l}\text { Regulating CoA } \\
\text { synthesis and } \\
\text { 1-butanol tolerance }\end{array}$ & $\begin{array}{l}\text { Synechocystis sp. } \\
\text { PCC } 6803\end{array}$ & Sun et al., 2017 \\
\hline PilR & 758305 & $210 \mathrm{nt}$ & $\begin{array}{l}\text { pilA9-pilA10- } \\
\text { pilA11-s/r2018 } \\
\text { operon }\end{array}$ & $\begin{array}{l}\text { Controlling pilA11 } \\
\text { gene expression } \\
\text { and cell motility }\end{array}$ & $\begin{array}{l}\text { Synechocystis sp. } \\
\text { PCC } 6803\end{array}$ & Hu et al., 2018 \\
\hline
\end{tabular}

TSS, transcription start sites; nt, nucleotides.

may regulate the tolerance to 1-butanol by downregulating the synthesis of $\mathrm{CoA}$, thus reducing fatty acid metabolism and energy metabolism (Sun et al., 2017). While in other cases, sRNAs are not coupled with cistrons expression, resulting in uncoordinated regulation of the operon. Cell motility relies on the expression of putative pilA9-pilA10-pilA11-slr2018 operon in Synechocystis sp. PCC 6803 (Panichkin et al., 2006). Recently, an asRNA PilR was identified in Synechocystis sp. PCC 6803, and it encoded in the non-coding strand of the prepilin-encoding gene pilA11 ( $\mathrm{Hu}$ et al., 2018). The PilR reduced the expression levels of pilA11, but no other gene in the pilA9-pilA10-pilA11-slr2018 operon, while reducing both the number and thickness of pili, limiting the motility of cells.

\section{Trans-Encoded Base Pairing sRNAs}

In cyanobacteria, in contrast to cis-encoded asRNAs, several of which have an in-depth study, another class of incomplete basepairing sRNAs is the trans-encoded sRNAs (Table 3). Sequence comparison of intergenic regions has revealed several transencoded sRNAs Yfr in several different cyanobacteria of the Prochlorococcus-Synechococcus lineage (Axmann et al., 2005). Of these, the Yfr2 sRNAs family (Yfr2-5) is a group of abundant RNA molecules and widely present in nearly all cyanobacteria sequenced to date (Gierga et al., 2009).

For trans-encoded sRNAs, the chromosomal location of the sRNA gene has little correlation with the target mRNA gene. The $y f r 1$ gene, a high conserved gene found in various cyanobacterial strains, is 65 nucleotides long and positioned between guaB and trxA in Synechococcus elongatus PCC 6301 (genome position: 2,417,299-2,417,363). However, the target $s b t A$ transcript of Yfr1 has a distant position (genome position: 2,623,057-2,624,178) (Nakamura et al., 2007). Furthermore, the $y$ fr1-disruption mutant, showed growth defects under various stress conditions.

In contrast to the cis-encoded asRNAs, the trans-encoded sRNAs modulate more than one target by formation of partial RNA-RNA duplexes. These sRNAs control the stability and translation of target mRNAs and have similar functions to eukaryotic miRNAs in many respects (Gottesman, 2005; Aiba, 2007). By computational and experimental data, sRNA PsrR1 has interaction with the ribosome-binding regions of the psaL, psaJ, $c h l N$, and cpcA mRNA in Synechocystis sp. PCC 6803 (Georg et al., 2014). As a regulatory factor for photosynthetic functions, sRNA PsrR1 and the transcriptional regulator RpaB constituted a feedforward loop to regulate PSI gene expression to achieve a rapid adaptive response to the high light stress condition (Kadowaki et al., 2016). Oxygenic photosynthesis depends to a large extent on proteins that contain $\mathrm{Fe}^{2+}$ or $\mathrm{Fe} / \mathrm{S}$ complexes as cofactors or prosthetic groups (Keren et al., 2004). Georg et al. showed that sRNA IsaR1 was induced by iron starvation and then acted on photosynthetic apparatus in three specific ways. The IsaR1 had more than 15 direct targets and controlled a complex network to acclimate to low iron condition (Georg et al., 2017). A transencoded sRNA Nc117 was discovered involved in the tolerance 


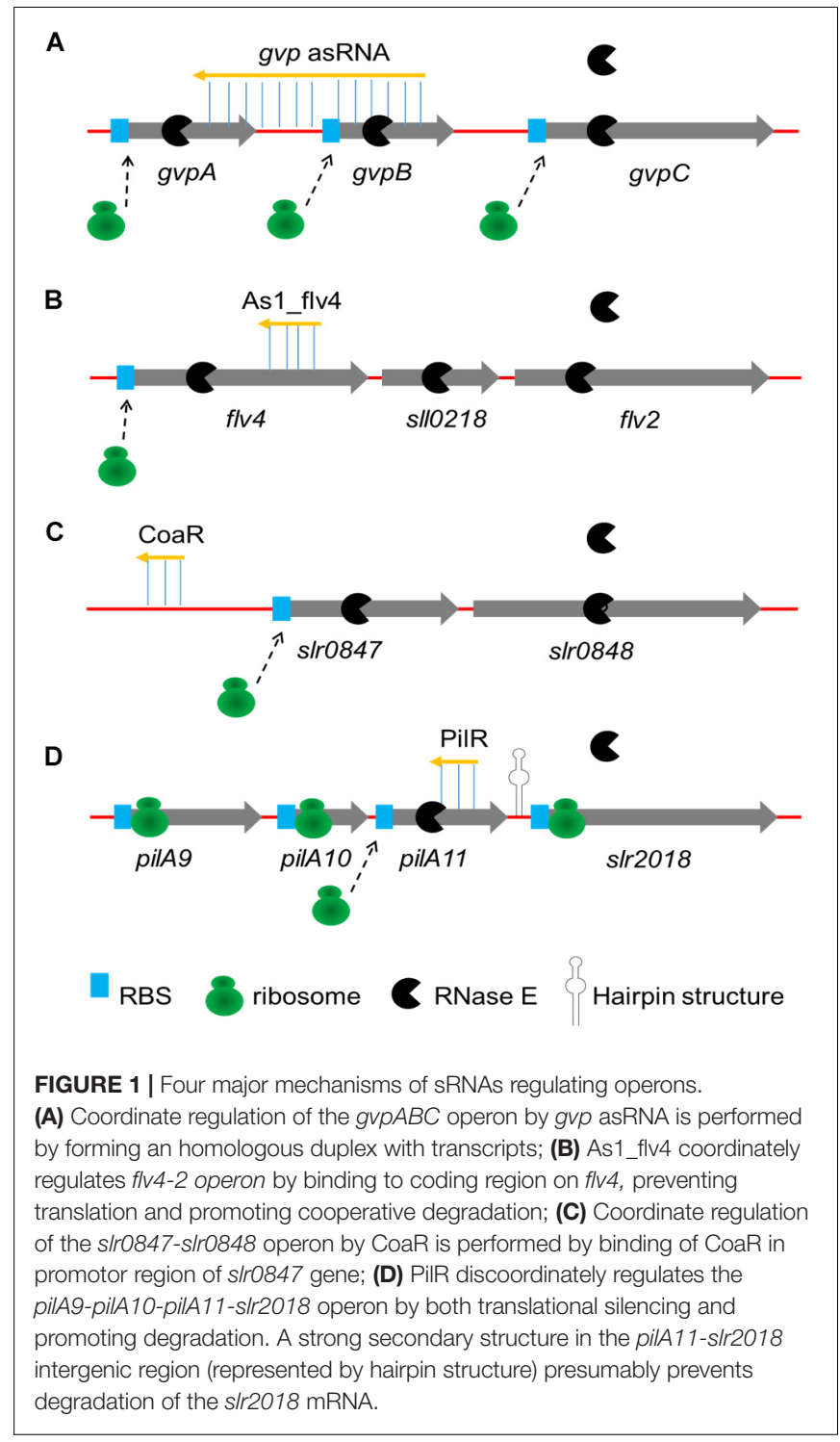

of Synechocystis sp. PCC 6803 to ethanol and 1-butanol (Pei et al., 2017). A total of 119 upregulated and 116 downregulated genes were identified by comparative transcriptomic analysis, among which a gene slr0007 encoding D-glycero-alpha-Dmannoheptose 1-phosphate guanylyltransferase was determined to be a potential target of $\mathrm{Nc117}$. These results suggested that the synthesis of lipopolysaccharide or S-layer glycoprotein may be related to the increased tolerance (Bi et al., 2018).

\section{Hfq Protein of RNA Chaperone}

In $E$. coli and closely related bacteria, the RNA chaperone Hfq usually participates in trans-encoded sRNA-mediated regulation, presumably to facilitate sRNA-mRNA duplex formation (Valentin-Hansen et al., 2004; Aiba, 2007; Brennan and Link, 2007). Several studies have found that hexameric Hfq ring was homologous to Sm and Sm-like proteins involved in mRNA decay and splicing in eukaryotes and archaea (ValentinHansen et al., 2004; Nielsen et al., 2007). In cyanobacteria, preliminary attempts to explore microbial genomes of $\mathrm{Hfq}$ homologs failed (Sun et al., 2002). However, combined with motif and pattern sequence searches, Hfq orthologs from various cyanobacteria were identified (Valentin-Hansen et al., 2004). The cyanobacterial Hfq homolog is proved to be essential for motility of Synechocystis sp. PCC 6803 through the knockout of $h f q$ (Dienst et al., 2008). The crystal structures of Hfq-homolog proteins retained the classic Sm folding despite low-sequence conservation in Synechocystis sp. PCC 6803 and Anabaena sp. PCC 7120 (Bøggild et al., 2009), suggesting the higher conservation of Hfq proteins in bacteria than initially anticipated (Table 4).

On the contrary, $\mathrm{Hfq}$ and homologue proteins are not ubiquitous in all of cyanobacteria. The $h f q$ has been lost in several sequenced Prochlorococcus strains, e.g., Prochlorococcus MED4 (Axmann et al., 2005; Steglich et al., 2008). The naturally $h f q-$ deficient Prochlorococcus MED4 expresses 24 different sRNAs (Axmann et al., 2005; Steglich et al., 2008). The phenomenon suggests that a class of sRNAs functions that do not require partner support of a chaperone or have a novel chaperone are yet to be identified.

\section{PHYSIOLOGICAL ROLES AND FUNCTIONS OF SRNA}

Although there has not been much research done, many sRNAs studied possessed important physiological roles and are related to environmental stresses, photosynthesis, $\mathrm{CO}_{2}$ fixation, and metabolism in the cyanobacteria (Table 5). Especially, transcoded sRNA and some cis-encoded asRNA respond generally to adverse environmental conditions by regulating metabolic pathways or alarm reaction. The asRNAs largely function against various environmental insults by the synthesis of target proteins, e.g., the target protein levels of IsiA (Dühring et al., 2006), Fur (Martin-Luna et al., 2011), PsbA2 and PsbA3 (Sakurai et al., 2012), RbcL (Hu et al., 2017), CoaD (Sun et al., 2017), and Flv42 (Eisenhut et al., 2012) are influenced by corresponding asRNA in iron-, light-, oxidative-, 1-butanol-stress, and carbon-limited conditions. Moreover, some sRNAs are required for growth under multiple stress conditions, e.g., the Synechococcus elongatus Yfr1, which has homologs in other cyanobacteria (Nakamura et al., 2007; Voss et al., 2007). The 14 new sRNA and 24 asRNA had been identified from intergenic regions of Prochlorococcus MED4 under various different stress conditions (Steglich et al., 2008). Some of these sRNAs expression profiles suggested involvement in bacteriophage infection response and/or light stress adaptation.

Cyanobacteria are usually obedient organisms for genetic manipulation, but the lack of powerful metabolic engineering tools has seriously restricted the attempts to implement more complex genetic regulation (Huang et al., 2010). In recent years, much attention has been paid to genetic tools based on artificial sRNAs as a result of their obvious superiority (Zess et al., 2016; Sun et al., 2018). Firstly, sRNA regulatory tools mostly do not impose any metabolic burden on host cells (Gaida et al., 2013). Secondly, the tunable base-pair 
TABLE 3 | Trans-encoded sRNAs indentified in cyanobacteria.

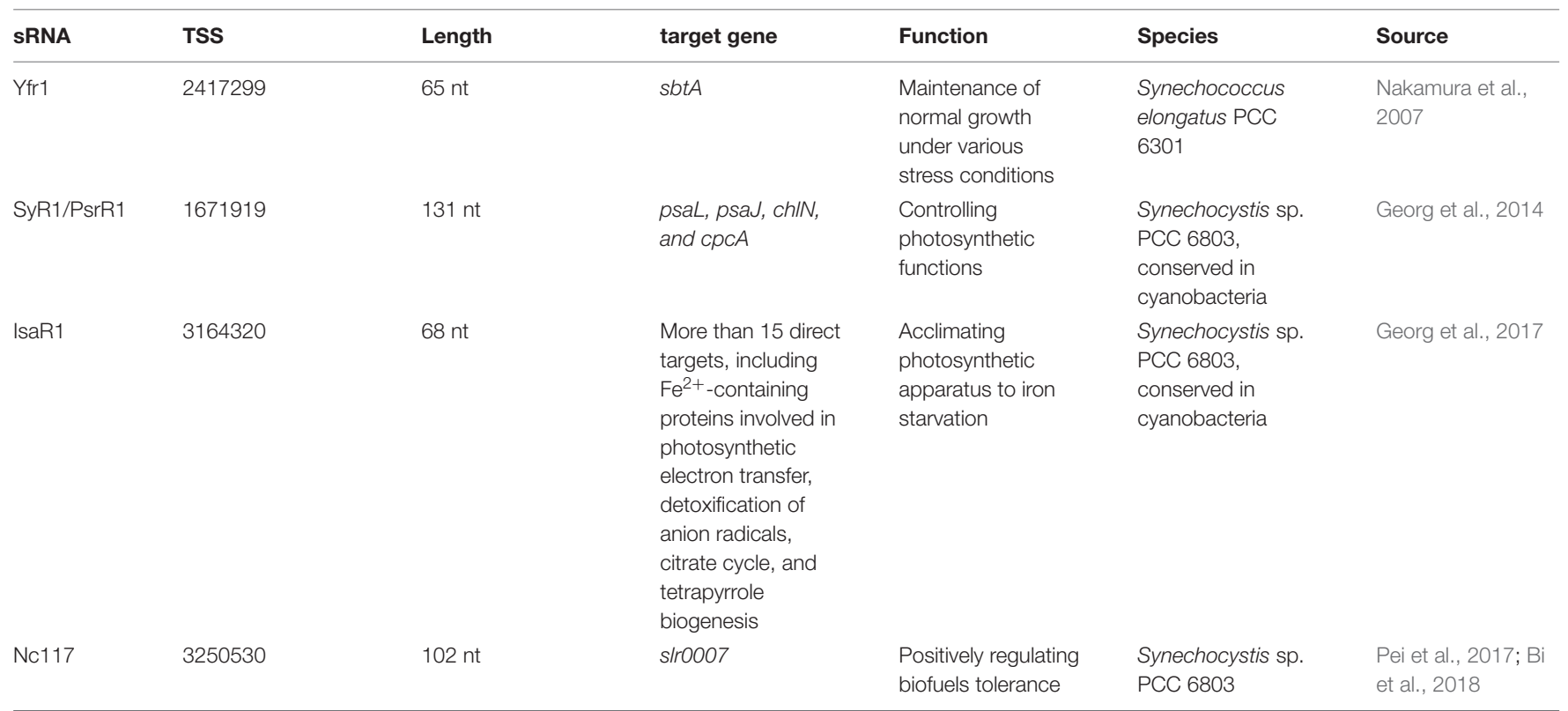

TSS, transcription start sites; $n t$, nucleotides.

TABLE 4 | Hfa protein of RNA chaperone in cyanobacteria.

\begin{tabular}{llll}
\hline RNA chaperone & Characteristic & Species & Source \\
\hline $\mathrm{Hfq}$ & Essential for cell motility & Synechocystis sp. PCC 6803 & Dienst et al., 2008 \\
$\mathrm{Hfq}$ & Retaining the classic Sm fold & Synechocystis sp. PCC 6803, Anabaena sp. PCC 7120 & Bøggild et al., 2009 \\
\hline
\end{tabular}

TABLE 5 | Physiological roles and functions of sRNAs in cyanobacteria.

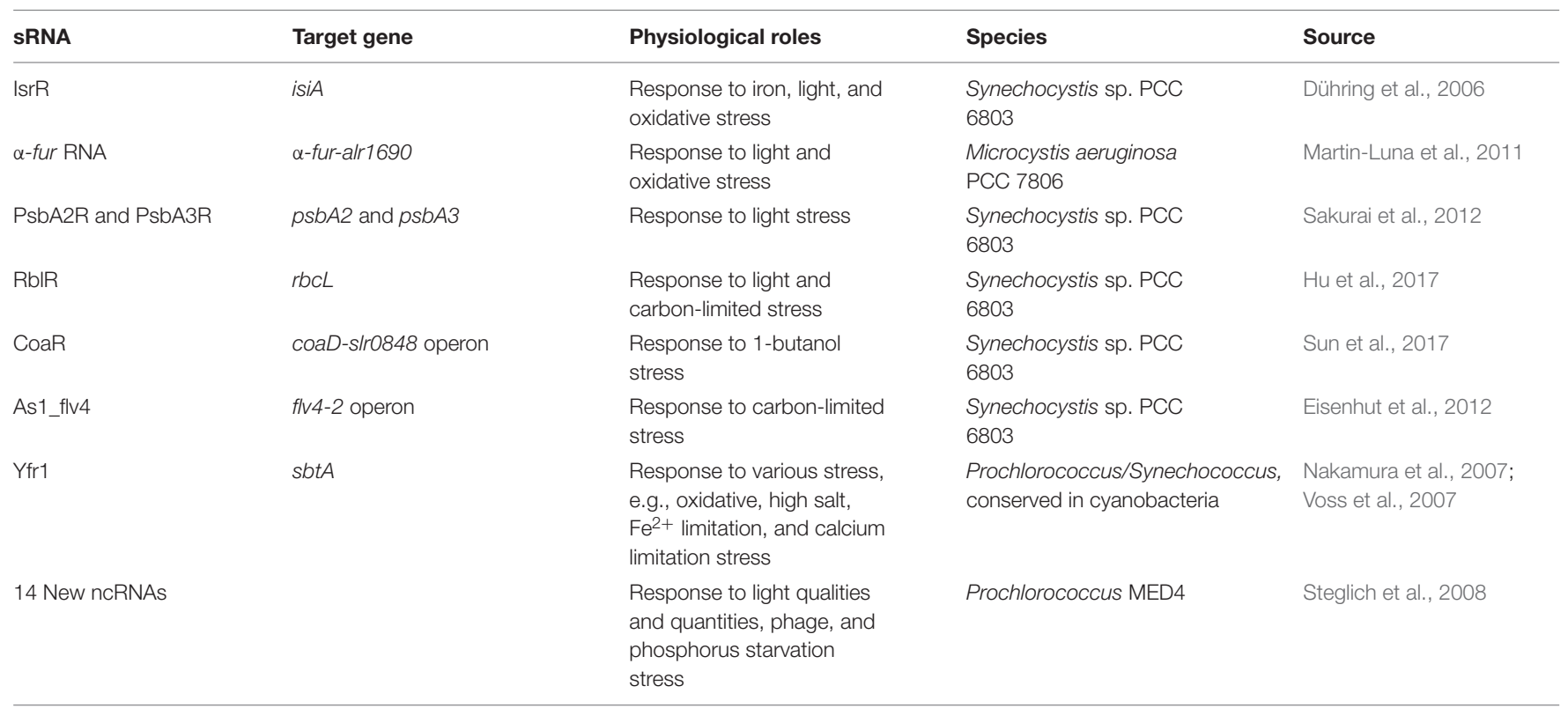

complementation sRNAs permit whole genome regulation of target genes for fine flux control (Rodrigo et al., 2012; Na et al., 2013). The last but not the least, sRNA regulatory tools could effectively knock the essential genes from the host cell, in contrast to the traditional lethal knockout method of these genes (Nakashima and Tamura, 2009). On the basis of interaction between sRNAs and their target mRNAs, some physiological and metabolic pathways of cyanobacteria can be modulated and altered by artificial sRNA tools. A trans-encoded sRNA system was constructed and adapted in Synechococcus sp. PCC 7002 
(Zess et al., 2016). This system exhibited 70\% depression of target gene expression, demonstrating sRNA regulatory tools for differential gene expression in cyanobacteria. Moreover, two sRNA regulatory tools were reported in Synechocystis sp. PCC 6803, which manipulated basic metabolic pathways and redirected carbon flux, based on a exogenous Hfq chaperone and a well-studied MicC scaffold previously developed in E. coli (Sun et al., 2018). For regulating multiple genes simultaneously and modifying into an inducible system, the Hfq-MicC tool was developed based on the theophylline-induced riboswitch. The sRNA regulatory tools introduce efficient and valuable metabolic and physiological regulatory strategies for cyanobacteria and, therefore, have showed promising applications.

\section{PROSPECT}

In recent years, approaches for sRNAs detecting and targeting have become a standard method used to search for several types of sRNA genes within bacterial genomes. Meanwhile, many target prediction tools and related software of bacteria have been developed. The sRNA regulatory systems are identified as efficient and valuable physiological regulatory strategies in cyanobacteria. Therefore, cyanobacterial sRNAs are well worth exploring as a strong and facile regulatory factor in future.

At present, RNA molecules hold many types of regulatory functions in bacteria and control almost all aspects of cell metabolism. A large number of sRNAs are intriguing as they may represent a mode of adaption under various environmental conditions. Regulation by sRNAs may require fewer resources than protein regulators synthesis (Shimoni et al., 2007; Mehta et al., 2008). Furthermore, there might be positive selection

\section{REFERENCES}

Abed, R. M., Dobretsov, S., and Sudesh, K. (2009). Applications of cyanobacteria in biotechnology. J. Appl. Microbiol. 106, 1-12. doi: 10.1111/j.1365-2672.2008. 03918.x

Aiba, H. (2007). Mechanism of RNA silencing by Hfq-binding small RNAs. Curr. Opin. Microbiol. 10, 134-139. doi: 10.1016/j.mib.2007.03.010

Axmann, I. M., Holtzendorff, J., Voss, B., Kensche, P., and Hess, W. R. (2007). Two distinct types of 6S RNA in Prochlorococcus. Gene 406, 69-78. doi: 10.1016/j. gene.2007.06.011

Axmann, I. M., Kensche, P., Vogel, J., Kohl, S., Herzel, H., and Hess, W. R. (2005). Identification of cyanobacterial non-coding RNAs by comparative genome analysis. Genome Biol. 6:R73. doi: 10.1186/gb-2005-6-9-r73

Backofen, R., and Hess, W. R. (2010). Computational prediction of sRNAs and their targets in bacteria. RNA Biol. 7, 33-42. doi: 10.4161/rna.7.1.10655

Banta, A. B., Haas, E. S., Brown, J. W., and Pace, N. R. (1992). Sequence of the ribonuclease P RNA gene from the cyanobacterium Anacystis nidulans. Nucleic Acids Res. 20:911. doi: 10.1093/nar/20.4.911

Barrick, J. E., Sudarsan, N., Weinberg, Z., Ruzzo, W. L., and Breaker, R. R. (2005). 6S RNA is a widespread regulator of eubacterial RNA polymerase that resembles an open promoter. RNA 11, 774-784. doi: 10.1261/rna.728 6705

Bi, Y., Pei, G., Sun, T., Chen, Z., Chen, L., and Zhang, W. (2018). Regulation mechanism mediated by trans-encoded sRNA Nc117 in short chain alcohols tolerance in Synechocystis sp. PCC 6803. Front. Microbiol. 9:863. doi: 10.3389/ fmicb.2018.00863

Bøggild, A., Overgaard, M., Valentin-Hansen, P., and Brodersen, D. E. (2009). Cyanobacteria contain a structural homologue of the Hfq protein with altered pressure to maintain small regulators rather than large protein regulators during genome reduction. Outstanding progress has been made in the identification and characterization of cyanobacterial sRNAs, indicating clearly that RNA regulators are ubiquitous and often conservative, possibly exceeding the number and diversity of protein regulators. However, many exciting questions about mechanism and function of some sRNAs still remain. The current focus is on developing tools to correctly predict sRNA targets. Several target prediction tools have been developed, but there are still considerable developments to be made. The identification of sRNA targets would allow the unraveling of pathways that involve sRNAinduced regulation. It would also be a further important step for the functional characterization of the many found sRNAs.

\section{AUTHOR CONTRIBUTIONS}

JH and QW gathered the information and wrote and edited the manuscript. QW revised and approved the work.

\section{FUNDING}

This work was supported by the National Natural Science Foundation of China (31770128, 31700055, and 31700107), the Fundamental Research Funds for the Central Universities (3102017OQD042), the China Postdoctoral Science Foundation (2017M610648), Shaanxi Provincial Postdoctoral Science Foundation (No. 2017BSHEDZZ102), and Shaanxi Provincial Natural Science Foundation (2018JQ3019).

RNA-binding properties. FEBS J. 276, 3904-3915. doi: 10.1111/j.1742-4658. 2009.07104.x

Brantl, S. (2007). Regulatory mechanisms employed by cis-encoded antisense RNAs. Curr. Opin. Microbiol. 10, 102-109. doi: 10.1016/j.mib.2007.03.012

Brennan, R. G., and Link, T. M. (2007). Hfq structure, function and ligand binding. Curr. Opin. Microbiol. 10, 125-133. doi: 10.1016/j.mib.2007. 03.015

Brown, J. W., Hunt, D. A., and Pace, N. R. (1990). Nucleotide sequence of the 10Sa RNA gene of the beta-purple eubacterium Alcaligenes eutrophus. Nucleic Acids Res. 18:2820. doi: 10.1093/nar/18.9.2820

Busch, A., Richter, A. S., and Backofen, R. (2008). IntaRNA: efficient prediction of bacterial sRNA targets incorporating target site accessibility and seed regions. Bioinformatics 24, 2849-2856. doi: 10.1093/bioinformatics/ btn544

Cao, Y., Zhao, Y., Cha, L., Ying, X., Wang, L., Shao, N., et al. (2009). sRNATarget: a web server for prediction of bacterial sRNA targets. Bioinformation 3, 364-366. doi: 10.6026/97320630003364

Chen, Z., Zhan, J., Chen, Y., Yang, M., He, C., Ge, F., et al. (2015). Effects of phosphorylation of beta subunits of phycocyanins on state transition in the model cyanobacterium Synechocystis sp. PCC 6803. Plant Cell Physiol. 56, 1997-2013. doi: 10.1093/pcp/pcv118

Csiszàr, K., Houmard, J., Damerval, T., and de Marsac, N. T. (1987). Transcriptional analysis of the cyanobacterial gvpABC operon in differentiated cells: occurrence of an antisense RNA complementary to three overlapping transcripts. Gene 60, 29-37. doi: 10.1016/0378-1119(87)90210-1

Dennis, G. Jr., Sherman, B. T., Hosack, D. A., Yang, J., Gao, W., Lane, H. C., et al. (2003). DAVID: database for annotation, visualization, and integrated discovery. Genome Biol. 4:P3. doi: 10.1186/gb-2003-4-5-p3 
Dienst, D., Dühring, U., Mollenkopf, H. -J., Vogel, J., Golecki, J., Hess, W. R., et al. (2008). The cyanobacterial homologue of the RNA chaperone Hfq is essential for motility of Synechocystis sp. PCC 6803. Microbiology 154, 3134-3143. doi: 10.1099/mic.0.2008/020222-0

Ditty, J., Williams, S., and Golden, S. (2003). A cyanobacterial circadian timing mechanism. Annu. Rev. Genet. 37, 513-543. doi: 10.1146/annurev.genet.37. 110801.142716

Dühring, U., Axmann, I. M., Hess, W. R., and Wilde, A. (2006). An internal antisense RNA regulates expression of the photosynthesis gene isiA. Proc. Natl. Acad. Sci. U.S.A. 103, 7054-7058. doi: 10.1073/pnas.0600927103

Eisenhut, M., Georg, J., Klahn, S., Sakurai, I., Mustila, H., Zhang, P., et al. (2012). The antisense RNA As1_flv4 in the cyanobacterium Synechocystis sp. PCC 6803 prevents premature expression of the flv4-2 operon upon shift in inorganic carbon supply. J. Biol. Chem. 287, 33153-33162. doi: 10.1074/jbc.M112.391755

Feller, U., Anders, I., and Mae, T. (2008). Rubiscolytics: fate of Rubisco after its enzymatic function in a cell is terminated. J. Exp. Bot. 59, 1615-1624. doi: $10.1093 / \mathrm{jxb} / \mathrm{erm} 242$

Fleischmann, R. D., Adams, M. D., White, O., Clayton, R. A., Kirkness, E. F., Kerlavage, A. R., et al. (1995). Whole-genome random sequencing and assembly of Haemophilus influenzae Rd. Science 269, 496-512. doi: 10.1126/science. 7542800

Flores, F. G., and Herrero, A. (2008). The Cyanobacteria: Molecular Biology, Genomics, and Evolution. Poole: Horizon Scientific Press.

Frank, D. N., and Pace, N. R. (1998). Ribonuclease P: unity and diversity in a tRNA processing ribozyme. Annu. Rev. Biochem. 67, 153-180. doi: 10.1146/annurev. biochem.67.1.153

Gaida, S. M., Al-Hinai, M. A., Indurthi, D. C., Nicolaou, S. A., and Papoutsakis, E. T. (2013). Synthetic tolerance: three noncoding small RNAs, DsrA, ArcZ and RprA, acting supra-additively against acid stress. Nucleic Acids Res. 41, 8726-8737. doi: 10.1093/nar/gkt651

Gaudin, C., Zhou, X., Williams, K. P., and Felden, B. (2002). Two-piece tmRNA in cyanobacteria and its structural analysis. Nucleic Acids Res. 30, 2018-2024. doi: $10.1093 /$ nar/30.9.2018

Georg, J., Dienst, D., Schurgers, N., Wallner, T., Kopp, D., Stazic, D., et al. (2014). The small regulatory RNA SyR1/PsrR1 controls photosynthetic functions in cyanobacteria. Plant Cell 26, 3661-3679. doi: 10.1105/tpc.114.129767

Georg, J., Kostova, G., Vuorijoki, L., Schon, V., Kadowaki, T., Huokko, T., et al. (2017). Acclimation of Oxygenic Photosynthesis to Iron Starvation Is Controlled by the sRNA IsaR1. Curr. Biol. 27, 1425.e7-1436.e7. doi: 10.1016/ j.cub.2017.04.010

Georg, J., Voss, B., Scholz, I., Mitschke, J., Wilde, A., and Hess, W. R. (2009). Evidence for a major role of antisense RNAs in cyanobacterial gene regulation. Mol. Syst. Biol. 5:305. doi: 10.1038/msb.2009.63

Gierga, G., Voss, B., and Hess, W. R. (2009). The Yfr2 ncRNA family, a group of abundant RNA molecules widely conserved in cyanobacteria. RNA Biol. 6, 222-227. doi: 10.4161/rna.6.3.8921

Giordano, M., and Wang, Q. (2018). "Microalgae for industrial purposes," in Biomass and Green Chemistry: Building a Renewable Pathway, ed. S. Vaz Jr. (Cham: Springer International Publishing), 133-167.

Goebel, N. L., Turk, K. A., Achilles, K. M., Paerl, R., Hewson, I., Morrison, A. E., et al. (2010). Abundance and distribution of major groups of diazotrophic cyanobacteria and their potential contribution to $\mathrm{N}(2)$ fixation in the tropical Atlantic Ocean. Environ. Microbiol. 12, 3272-3289. doi: 10.1111/j.1462-2920. 2010.02303.x

Gottesman, S. (2005). Micros for microbes: non-coding regulatory RNAs in bacteria. Trends Genet. 21, 399-404. doi: 10.1016/j.tig.2005.05.008

Hernandez, J. A., Alonso, I., Pellicer, S., Luisa Peleato, M., Cases, R., Strasser, R. J., et al. (2010). Mutants of Anabaena sp. PCC 7120 lacking alr1690 and alphafurA antisense RNA show a pleiotropic phenotype and altered photosynthetic machinery. J. Plant Physiol. 167, 430-437. doi: 10.1016/j.jplph.2009.1 0.009

Hernández, J. A., Muro-Pastor, A. M., Flores, E., Bes, M. T., Peleato, M. L., and Fillat, M. F. (2006). Identification of a furA cis Antisense RNA in the Cyanobacterium Anabaena sp. PCC 7120. J. Mol. Biol. 355, 325-334. doi: 10. 1016/j.jmb.2005.10.079

Hu, J., Li, T., Xu, W., Zhan, J., Chen, H., He, C., et al. (2017). Small antisense RNA RblR positively regulates RuBisCo in Synechocystis sp. PCC 6803. Front. Microbiol. 8:231. doi: 10.3389/fmicb.2017.00231
Hu, J., Zhan, J., Chen, H., He, C., Cang, H., and Wang, Q. (2018). The small regulatory antisense RNA PilR affects pilus formation and cell motility by negatively regulating pilA11 in Synechocystis sp. PCC 6803. Front. Microbiol. 9:786. doi: 10.3389/fmicb.2018.00786

Huang, D. W., Sherman, B. T., and Lempicki, R. A. (2008). Systematic and integrative analysis of large gene lists using DAVID bioinformatics resources. Nat. Protoc. 4, 44-57. doi: 10.1038/nprot.2008.211

Huang, H. H., Camsund, D., Lindblad, P., and Heidorn, T. (2010). Design and characterization of molecular tools for a synthetic biology approach towards developing cyanobacterial biotechnology. Nucleic Acids Res. 38, 2577-2593. doi: $10.1093 /$ nar/gkq164

Huttenhofer, A., Brosius, J., and Bachellerie, J. P. (2002). RNomics: identification and function of small, non-messenger RNAs. Curr. Opin. Microbiol. 6, 835-843.

Huttenhofer, A., Schattner, P., and Polacek, N. (2005). Non-coding RNAs: hope or hype? Trends Genet. 21, 289-297. doi: 10.1016/j.tig.2005.03.007

Hüttenhofer, A., and Vogel, J. (2006). Experimental approaches to identify noncoding RNAs. Nucleic Acids Res. 34, 635-646. doi: 10.1093/nar/gkj469

Kadowaki, T., Nagayama, R., Georg, J., Nishiyama, Y., Wilde, A., Hess, W. R., et al. (2016). A feed-forward loop consisting of the response regulator RpaB and the small RNA PsrR1 controls light acclimation of photosystem i gene expression in the cyanobacterium Synechocystis sp. PCC 6803. Plant Cell Physiol. 57, 813-823. doi: $10.1093 / \mathrm{pcp} / \mathrm{pcw} 028$

Kaneko, T., and Tabata, S. (1997). Complete genome structure of the unicellular cyanobacterium Synechocystis sp. PCC6803. Plant Cell Physiol. 38, 1171-1176. doi: 10.1093/oxfordjournals.pcp.a029103

Keiler, K. C., Shapiro, L., and Williams, K. P. (2000). tmRNAs that encode proteolysis-inducing tags are found in all known bacterial genomes: a two-piece tmRNA functions in Caulobacter. Proc. Natl. Acad. Sci. U.S.A. 97, 7778-7783. doi: $10.1073 /$ pnas.97.14.7778

Keren, N., Aurora, R., and Pakrasi, H. B. (2004). Critical roles of bacterioferritins in iron storage and proliferation of cyanobacteria. Plant Physiol. 135, 1666-1673. doi: 10.1104/pp.104.042770

Kopf, M., Klahn, S., Scholz, I., Matthiessen, J. K., Hess, W. R., and Voss, B. (2014). Comparative analysis of the primary transcriptome of Synechocystis sp. PCC 6803. DNA Res. 21, 527-539. doi: 10.1093/dnares/dsu018

Landt, S. G., Abeliuk, E., McGrath, P. T., Lesley, J. A., McAdams, H. H., and Shapiro, L. (2008). Small non-coding RNAs in Caulobacter crescentus. Mol. Microbiol. 68, 600-614. doi: 10.1111/j.1365-2958.2008.06172.x

Lee, E. J., and Groisman, E. A. (2010). An antisense RNA that governs the expression kinetics of a multifunctional virulence gene. Mol. Microbiol. 76, 1020-1033. doi: 10.1111/j.1365-2958.2010.07161.x

Legewie, S., Dienst, D., Wilde, A., Herzel, H., and Axmann, I. M. (2008). Small RNAs establish delays and temporal thresholds in gene expression. Biophys. J. 95, 3232-3238. doi: 10.1529/biophysj.108.133819

Livny, J., Teonadi, H., Livny, M., and Waldor, M. K. (2008). High-throughput, kingdom-wide prediction and annotation of bacterial non-coding RNAs. PLoS One 3:e3197. doi: 10.1371/journal.pone.0003197

Livny, J., and Waldor, M. K. (2007). Identification of small RNAs in diverse bacterial species. Curr. Opin. Microbiol. 10, 96-101. doi: 10.1016/j.mib.2007. 03.005

Lott, S. C., Schafer, R. A., Mann, M., Backofen, R., Hess, W. R., Voss, B., et al. (2018). GLASSgo - automated and reliable detection of sRNA homologs from a single input sequence. Front. Genet. 9:124. doi: 10.3389/fgene.2018.00124

Ma, F., Zhang, X., Zhu, X., Li, T., Zhan, J., Chen, H., et al. (2017). Dynamic changes of IsiA-containing complexes during long-term iron deficiency in Synechocystis sp. PCC 6803. Mol. Plant 10, 143-154. doi: 10.1016/j.molp.2016.10.009

Mandin, P., Repoila, F., Vergassola, M., Geissmann, T., and Cossart, P. (2007). Identification of new noncoding RNAs in Listeria monocytogenes and prediction of mRNA targets. Nucleic Acids Res. 35, 962-974. doi: 10.1093/nar/gkl1096

Martin-Luna, B., Sevilla, E., Gonzalez, A., Bes, M. T., Fillat, M. F., and Peleato, M. L. (2011). Expression of fur and its antisense alpha-fur from Microcystis aeruginosa PCC7806 as response to light and oxidative stress. J. Plant Physiol. 168, 2244-2250. doi: 10.1016/j.jplph.2011.08.006

Mattick, J. S. (2001). Non-coding RNAs: the architects of eukaryotic complexity. EMBO Rep. 2, 986-991. doi: 10.1093/embo-reports/kve230

Mehta, P., Goyal, S., and Wingreen, N. S. (2008). A quantitative comparison of sRNA-based and protein-based gene regulation. Mol. Syst. Biol. 4:221. doi: $10.1038 / \mathrm{msb} .2008 .58$ 
Mitschke, J., Georg, J., Scholz, I., Sharma, C. M., Dienst, D., Bantscheff, J., et al. (2011a). An experimentally anchored map of transcriptional start sites in the model cyanobacterium Synechocystis sp. PCC6803. Proc. Natl. Acad. Sci. U.S.A. 108, 2124-2129. doi: 10.1073/pnas.1015154108

Mitschke, J., Vioque, A., Haas, F., Hess, W. R., and Muro-Pastor, A. M. (2011b). Dynamics of transcriptional start site selection during nitrogen stress-induced cell differentiation in Anabaena sp. PCC7120. Proc. Natl. Acad. Sci. U.S.A. 108, 20130-20135. doi: 10.1073/pnas.1112724108

Mizuno, T., Chou, M. Y., and Inouye, M. (1984). A unique mechanism regulating gene expression: translational inhibition by a complementary RNA transcript (micRNA). Proc. Natl. Acad. Sci. U.S.A. 81, 1966-1970. doi: 10.1073/pnas.81.7. 1966

Muckstein, U., Tafer, H., Hackermuller, J., Bernhart, S. H., Stadler, P. F., and Hofacker, I. L. (2006). Thermodynamics of RNA-RNA binding. Bioinformatics 22, 1177-1182. doi: 10.1093/bioinformatics/btl024

Na, D., Yoo, S. M., Chung, H., Park, H., Park, J. H., and Lee, S. Y. (2013). Metabolic engineering of Escherichia coli using synthetic small regulatory RNAs. Nat. Biotechnol. 31, 170-174. doi: 10.1038/nbt.2461

Nair, U., Ditty, J. L., Min, H., and Golden, S. S. (2002). Roles for sigma factors in global circadian regulation of the cyanobacterial genome. J. Bacteriol. 184, 3530-3538. doi: 10.1128/JB.184.13.3530-3538.2002

Nakamura, T., Naito, K., Yokota, N., Sugita, C., and Sugita, M. (2007). A cyanobacterial non-coding RNA, Yfr1, is required for growth under multiple stress conditions. Plant Cell Physiol. 48, 1309-1318. doi: 10.1093/pcp/pcm098

Nakashima, N., and Tamura, T. (2009). Conditional gene silencing of multiple genes with antisense RNAs and generation of a mutator strain of Escherichia coli. Nucleic Acids Res. 37:e103. doi: 10.1093/nar/gkp498

Nielsen, J. S., Bøggild, A., Andersen, C. B., Nielsen, G., Boysen, A., Brodersen, D. E., et al. (2007). An Hfq-like protein in archaea: crystal structure and functional characterization of the Sm protein from Methanococcus jannaschii. RNA 13, 2213-2223. doi: 10.1261/rna.689007

Panichkin, V. B., Arakawa-Kobayashi, S., Kanaseki, T., Suzuki, I., Los, D. A., Shestakov, S. V., et al. (2006). Serine/threonine protein kinase SpkA in Synechocystis sp. strain PCC 6803 is a regulator of expression of three putative pilA operons, formation of thick pili, and cell motility. J. Bacteriol. 188, 7696-7699. doi: 10.1128/JB.00838-06

Park, S.-Y., Cromie, M. J., Lee, E.-J., and Groisman, E. A. (2010). A bacterial mRNA leader that employs different mechanisms to sense disparate intracellular signals. Cell 142, 737-748. doi: 10.1016/j.cell.2010.07.046

Pei, G., Sun, T., Chen, S., Chen, L., and Zhang, W. (2017). Systematic and functional identification of small non-coding RNAs associated with exogenous biofuel stress in cyanobacterium Synechocystis sp. PCC 6803. Biotechnol. Biofuels 10:57. doi: 10.1186/s13068-017-0743-y

Pisciotta, J. M., Zou, Y., and Baskakov, I. V. (2010). Light-dependent electrogenic activity of cyanobacteria. PLoS One 5:e10821. doi: 10.1371/journal.pone. 0010821

Quintana, N., Kooy, F., Rhee, M., Voshol, G., and Verpoorte, R. (2011). Renewable energy from Cyanobacteria: energy production optimization by metabolic pathway engineering. Appl. Microbiol. Biotechnol. 91, 471-490. doi: 10.1007/ s00253-011-3394-0

Raghavan, R., Groisman, E. A., and Ochman, H. (2011). Genome-wide detection of novel regulatory RNAs in E. coli. Genome Res. 21, 1487-1497. doi: 10.1101/ gr.119370.110

Ray, B. K., and Apirion, D. (1979). Characterization of 10S RNA: a new stable RNA molecule from Escherichia coli. Mol. Gen. Genet. 174, 25-32. doi: 10.1007/ BF00433301

Rehmsmeier, M., Steffen, P., Hochsmann, M., and Giegerich, R. (2004). Fast and effective prediction of microRNA/target duplexes. RNA 10, 1507-1517. doi: 10.1261/rna.5248604

Rodrigo, G., Landrain, T. E., and Jaramillo, A. (2012). De novo automated design of small RNA circuits for engineering synthetic riboregulation in living cells. Proc. Natl. Acad. Sci. U.S.A. 109, 15271-15276. doi: 10.1073/pnas.12038 31109

Romby, P., Vandenesch, F., and Wagner, E. G. (2006). The role of RNAs in the regulation of virulence-gene expression. Curr. Opin. Microbiol. 9, 229-236. doi: 10.1016/j.mib.2006.02.005

Sakurai, I., Stazic, D., Eisenhut, M., Vuorio, E., Steglich, C., Hess, W. R., et al. (2012). Positive regulation of psbA gene expression by cis-encoded antisense
RNAs in Synechocystis sp. PCC 6803. Plant Physiol. 160, 1000-1010. doi: 10. 1104/pp.112.202127

Schon, A., Fingerhut, C., and Hess, W. R. (2002). Conserved and variable domains within divergent rnase P RNA gene sequences of Prochlorococcus strains. Int. J. Syst. Evol. Microbiol. 52(Pt 4), 1383-1389.

Schopf, J. W. (1993). Microfossils of the early archean apex chert: new evidence of the antiquity of life. Science 260, 640-646. doi: 10.1126/science.260.5108.640

Sevilla, E., Martin-Luna, B., Gonzalez, A., Gonzalo-Asensio, J. A., Peleato, M. L., and Fillat, M. F. (2011). Identification of three novel antisense RNAs in the fur locus from unicellular cyanobacteria. Microbiology 157(Pt 12), 3398-3404 doi: 10.1099/mic.0.048231-0

Shimoni, Y., Friedlander, G., Hetzroni, G., Niv, G., Altuvia, S., Biham, O., et al. (2007). Regulation of gene expression by small non-coding RNAs: a quantitative view. Mol. Syst. Biol. 3:138. doi: 10.1038/msb4100181

Simons, R. W., and Kleckner, N. (1983). Translational control of IS10 transposition. Cell 34, 683-691. doi: 10.1016/0092-8674(83)90401-4

Sittka, A., Lucchini, S., Papenfort, K., Sharma, C. M., Rolle, K., Binnewies, T. T., et al. (2008). Deep sequencing analysis of small noncoding RNA and mRNA targets of the global post-transcriptional regulator, Hfq. PLoS Genet. 4:e1000163. doi: 10.1371/journal.pgen.1000163

Spreitzer, R. J., and Salvucci, M. E. (2002). Rubisco: structure, regulatory interactions, and possibilities for a better enzyme. Annu. Rev. Plant Biol. 53, 449-475. doi: 10.1146/annurev.arplant.53.100301.135233

Steglich, C., Futschik, M. E., Lindell, D., Voss, B., Chisholm, S. W., and Hess, W. R. (2008). The challenge of regulation in a minimal photoautotroph: non-coding RNAs in Prochlorococcus. PLoS Genet. 4:e1000173. doi: 10.1371/journal.pgen. 1000173

Storz, G. (2002). An expanding universe of noncoding RNAs. Science 296, 1260-1263. doi: 10.1126/science.1072249

Storz, G., Opdyke, J. A., and Zhang, A. (2004). Controlling mRNA stability and translation with small, noncoding RNAs. Curr. Opin. Microbiol. 7, 140-144. doi: 10.1016/j.mib.2004.02.015

Stougaard, P., Molin, S., and Nordström, K. (1981). RNAs involved in copynumber control and incompatibility of plasmid R1. Proc. Natl. Acad. Sci. U.S.A. 78, 6008-6012. doi: 10.1073/pnas.78.10.6008

Sugita, C., Ogata, K., Shikata, M., Jikuya, H., Takano, J., Furumichi, M., et al. (2007). Complete nucleotide sequence of the freshwater unicellular cyanobacterium Synechococcus elongatus PCC 6301 chromosome: gene content and organization. Photosynth. Res. 93, 55-67. doi: 10.1007/s11120-006-9122-4

Sun, T., Li, S., Song, X., Pei, G., Diao, J., Cui, J., et al. (2018). Re-direction of carbon flux to key precursor malonyl-CoA via artificial small RNAs in photosynthetic Synechocystis sp. PCC 6803. Biotechnol. Biofuels 11:26. doi: 10.1186/s130 68-018-1032-0

Sun, T., Pei, G., Wang, J., Chen, L., and Zhang, W. (2017). A novel small RNA CoaR regulates coenzyme A biosynthesis and tolerance of Synechocystis sp. PCC6803 to 1-butanol possibly via promoter-directed transcriptional silencing. Biotechnol. Biofuels 10:42. doi: 10.1186/s13068-017-0727-y

Sun, X., Zhulin, I., and Wartell, R. M. (2002). Predicted structure and phyletic distribution of the RNA-binding protein Hfq. Nucleic Acids Res. 30, 3662-3671. doi: $10.1093 /$ nar/gkf508

Tafer, H., and Hofacker, I. L. (2008). RNAplex: a fast tool for RNA-RNA interaction search. Bioinformatics 24, 2657-2663. doi: 10.1093/bioinformatics/btn193

Tamagnini, P., Axelsson, R., Lindberg, P., Oxelfelt, F., Wünschiers, R., and Lindblad, P. (2002). Hydrogenases and hydrogen metabolism of cyanobacteria. Microbiol. Mol. Biol. Rev. 66, 1-20. doi: 10.1128/MMBR.66.1.120.2002

Tjaden, B. (2008). TargetRNA: a tool for predicting targets of small RNA action in bacteria. Nucleic Acids Res. 36, W109-W113. doi: 10.1093/nar/gkn264

Tjaden, B., Goodwin, S. S., Opdyke, J. A., Guillier, M., Fu, D. X., Gottesman, S., et al. (2006). Target prediction for small, noncoding RNAs in bacteria. Nucleic Acids Res. 34, 2791-2802. doi: 10.1093/nar/gkl356

Tomizawa, J., Itoh, T., Selzer, G., and Som, T. (1981). Inhibition of ColE1 RNA primer formation by a plasmid-specified small RNA. Proc. Natl. Acad. Sci. U.S.A. 78, 1421-1425. doi: 10.1073/pnas.78.3.1421

Tous, C., Vega-Palas, M. A., and Vioque, A. (2001). Conditional expression of RNase P in the cyanobacterium Synechocystis sp. PCC6803 allows detection of precursor RNAs. J. Biol. Chem. 276, 29059-29066. doi: 10.1074/jbc. M103418200 
Tyagi, J. S., and Kinger, A. K. (1992). Identification of the 10Sa RNA structural gene of Mycobacterium tuberculosis. Nucleic Acids Res. 20, 138-138. doi: 10.1093/nar/ 20.1.138

Ushida, C., Himeno, H., Watanabe, T., and Muto, A. (1994). tRNA-like structures in 10Sa RNAs of Mycoplasma capricolum and Bacillus subtilis. Nucleic Acids Res. 22, 3392-3396. doi: 10.1093/nar/22.16.3392

Valentin-Hansen, P., Eriksen, M., and Udesen, C. (2004). The bacterial Sm-like protein Hfq: a key player in RNA transactions. Mol. Microbiol. 51, 1525-1533. doi: 10.1111/j.1365-2958.2003.03935.x

Volpe, T. A., Kidner, C., Hall, I. M., Teng, G., Grewal, S. I., and Martienssen, R. A. (2002). Regulation of heterochromatic silencing and histone H3 lysine-9 methylation by RNAi. Science 297, 1833-1837. doi: 10.1126/science.1074973

Voss, B., Georg, J., Schon, V., Ude, S., and Hess, W. R. (2009). Biocomputational prediction of non-coding RNAs in model cyanobacteria. BMC Genomics 10:123. doi: 10.1186/1471-2164-10-123

Voss, B., Gierga, G., Axmann, I. M., and Hess, W. R. (2007). A motif-based search in bacterial genomes identifies the ortholog of the small RNA Yfr1 in all lineages of cyanobacteria. BMC Genomics 8:375. doi: 10.1186/1471-2164-8-375

Wagner, E. G. H., Altuvia, S., and Romby, P. (2002). 12 Antisense RNAs in bacteria and their genetic elements. Adv. Genet. 46, 361-398. doi: 10.1016/ S0065-2660(02)46013-0

Wang, Q., Jantaro, S., Lu, B., Majeed, W., Bailey, M., and He, Q. (2008). The high light-inducible polypeptides stabilize trimeric photosystem I complex under high light conditions in Synechocystis PCC 6803. Plant Physiol. 147, 1239-1250. doi: $10.1104 /$ pp.108.121087

Wassarman, K. M., Zhang, A., and Storz, G. (1999). Small RNAs in Escherichia coli. Trends Microbiol. 7, 37-45. doi: 10.1016/S0966-842X(98) 01379-1

Watanabe, T., Sugita, M., and Sugiura, M. (1998). Identification of 10Sa RNA (tmRNA) homologues from the cyanobacterium Synechococcus sp. strain PCC6301 and related organisms. Biochim. Biophys. Acta Biomembranes 1396, 97-104. doi: 10.1016/S0167-4781(97)00180-2

Watanabe, T., Sugiura, M., and Sugita, M. (1997). A novel small stable RNA, 6Sa RNA, from the cyanobacterium Synechococcus sp. strain PCC6301. FEBS Lett. 416, 302-306. doi: 10.1016/S0014-5793(97)01237-4

Waters, L. S., and Storz, G. (2009). Regulatory RNAs in bacteria. Cell 136, 615-628. doi: 10.1016/j.cell.2009.01.043

Weinberg, Z., Barrick, J. E., Yao, Z., Roth, A., Kim, J. N., Gore, J., et al. (2007). Identification of 22 candidate structured RNAs in bacteria using the CMfinder comparative genomics pipeline. Nucleic Acids Res. 35, 4809-4819. doi: 10.1093/ Nar/Gkm487

Williams, K. P., and Bartel, D. P. (1996). Phylogenetic analysis of tmRNA secondary structure. RNA 2, 1306-1310.

Wright, P. R., Georg, J., Mann, M., Sorescu, D. A., Richter, A. S., Lott, S., et al. (2014). CopraRNA and IntaRNA: predicting small RNA targets, networks and interaction domains. Nucleic Acids Res. 42, W119-W123. doi: 10.1093/nar/ gku359

Xu, W., Chen, H., He, C. L., and Wang, Q. (2014). Deep sequencing-based identification of small regulatory RNAs in Synechocystis sp. PCC 6803. PLoS One 9:e92711. doi: 10.1371/journal.pone.0092711

Zess, E. K., Begemann, M. B., and Pfleger, B. F. (2016). Construction of new synthetic biology tools for the control of gene expression in the cyanobacterium Synechococcus sp. strain PCC 7002. Biotechnol. Bioeng. 113, 424-432. doi: 10. 1002/bit. 25713

Zhan, J., and Wang, Q. (2018). "Photoresponse mechanism in cyanobacteria: key factor in photoautotrophic chassis," in Synthetic Biology of Cyanobacteria, eds W. Zhang \& X. Song (Singapore: Springer Singapore), 75-96.

Zhang, P., Allahverdiyeva, Y., Eisenhut, M., and Aro, E. M. (2009). Flavodiiron proteins in oxygenic photosynthetic organisms: photoprotection of photosystem II by Flv2 and Flv4 in Synechocystis sp. PCC 6803. PLoS One 4:e5331. doi: 10.1371/journal.pone.0005331

Zhang, P., Eisenhut, M., Brandt, A. -M., Carmel, D., Silén, H. M., Vass, I., et al. (2012). Operon flv4-flv2 provides cyanobacterial photosystem II with flexibility of electron transfer. Plant Cell 24, 1952-1971. doi: 10.1105/tpc.111.094417

Zhao, Y., Li, H., Hou, Y., Cha, L., Cao, Y., Wang, L., et al. (2008). Construction of two mathematical models for prediction of bacterial sRNA targets. Biochem. Biophys. Res. Commun. 372, 346-350. doi: 10.1016/j.bbrc.2008.05.046

Conflict of Interest Statement: The authors declare that the research was conducted in the absence of any commercial or financial relationships that could be construed as a potential conflict of interest.

Copyright (c) $2018 \mathrm{Hu}$ and Wang. This is an open-access article distributed under the terms of the Creative Commons Attribution License (CC BY). The use, distribution or reproduction in other forums is permitted, provided the original author(s) and the copyright owner(s) are credited and that the original publication in this journal is cited, in accordance with accepted academic practice. No use, distribution or reproduction is permitted which does not comply with these terms. 